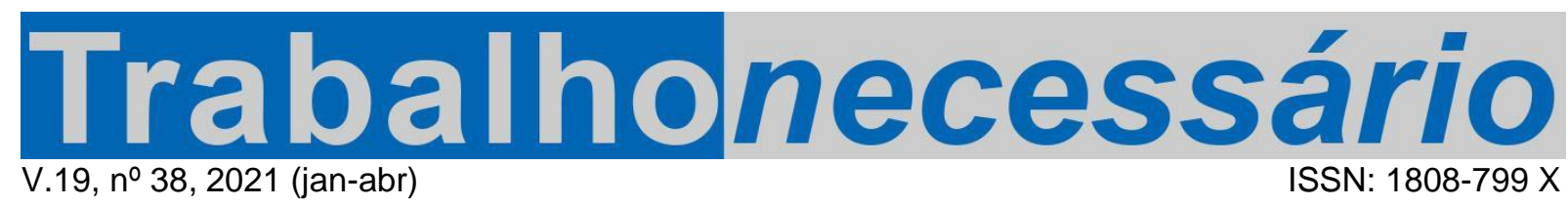

\title{
A DIVISÃO SEXUAL DO TRABALHO NO CONTEXTO DA PANDEMIA ${ }^{1}$
}

\author{
Hildete Pereira de Melo² \\ Lucilene Morandi ${ }^{3}$
}

\section{Resumo}

Este artigo tem como propósito fazer uma análise conjuntural da economia brasileira nestes meses de crise sanitária sem precedentes em sua história, tendo como fio condutor e pano de fundo a divisão sexual do trabalho. A pandemia da Covid-19 irrompeu em meio à crise econômica que a economia brasileira amargava desde 2015, com baixas taxas de crescimento desde 2017. Para as mulheres, a estagnação econômica e a crise sanitária potencializaram as desigualdades relativas ao mercado de trabalho e à divisão das tarefas de cuidado dentro da família.

Palavras-chave: gênero; desigualdade; crise sanitária; crise econômica.

\section{LA DIVISIÓN SEXUAL DEL TRABAJO EM EL CONTEXTO DE LA PANDEMIA}

\section{Resumen}

El propósito de este artículo es hacer un análisis coyuntural de la economía brasileña en estos meses de crisis de salud sin precedentes en su historia, tomando la perspectiva de la división sexual del trabajo. La economía brasileña vivía una crisis económica desde 2015, con bajas tasas de crecimiento desde 2017, cuando irrumpió la pandemia de Covid-19. Para las mujeres, el estancamiento económico y la crisis de salud han intensificado las desigualdades del mercado laboral y de la división de tareas de cuidado dentro de la familia.

Palabras clave: género; desigualdad; crisis de salud; crisis económica.

\section{THE SEXUAL DIVISION OF WORK IN THE CONTEXT OF THE PANDEMIA}

\begin{abstract}
The purpose of this article is to make a conjectural analysis of Brazilian economy in these months of health crisis unprecedented in its history, with the sexual division of labor as the guiding thread and background. The Coronavirus pandemic erupted in the midst of the economic crisis that the Brazilian economy has suffered since 2015, with very low growth rates since 2017. For women, economic stagnation and the healthy crisis have increased inequalities related to the labor market and the division of care work within the family.

Key words: gender; inequalities; sanitary crisis; economic crisis.
\end{abstract}

\footnotetext{
1 Artigo recebido em 11/09/2020. Primeira avaliação em 01/10/2020. Segunda avaliação em 05/10/2020. Terceira avaliação em 23/10/2020. Aprovado em 01/12/2020. Publicado em 25/02/2021. DOI: https://doi.org/10.22409/tn.v19i38.45884.

2 Doutora em Economia, Professora da Faculdade de Economia e do Programa de Pós-Graduação em Políticas Sociais, Pesquisadora sênior do Núcleo de Pesquisa em Gênero e Economia (NPGE) da Universidade Federal Fluminense (UFF). E-mail: hildete43@gmail.com.

ORCID: 0000-0002-9701- 7890.

${ }^{3}$ Doutora em Economia, Professora associada da Faculdade de Economia, Coordenadora do Núcleo de Pesquisa em Gênero e Economia (NPGE) da Universidade Federal Fluminense (UFF).

E-mail: Imorandi@id.uff.br. ORCID: 0000-0002-3943-6229.
} 


\section{Introdução}

A pandemia da Covid-19 atingiu o Brasil em um momento particularmente difícil, dado que a economia vinha de uma grave crise econômica, em 2015 e 2016, e apresentando baixa capacidade de recuperação desde então. A pandemia colaborou para agravar o quadro de baixo crescimento econômico com alto nível de desemprego, ampliando as desigualdades já bastante severas, numa economia em que parte significativa da força de trabalho (41,6\% em 2019) estava na informalidade, o que aumentou a vulnerabilidade das famílias de menor renda.

Os efeitos econômicos adversos, decorrentes do isolamento social necessário para reduzir o contágio durante a pandemia, não tiveram o mesmo impacto em homens e mulheres trabalhadoras e isso ampliou a desigualdade de gênero no país. Isso porque as mulheres são maioria nos postos de trabalho relacionados a cuidados, como trabalhadoras domésticas, em que a maioria $(76,4 \%)$ é contratada informalmente, sem carteira assinada; como cuidadoras contratadas diretamente pelas famílias ou através de empresas; ou como trabalhadoras nos serviços de saúde (as mulheres são 65\% dos trabalhadores desse setor). ${ }^{4}$

Durante a pandemia, de um lado, alguns desses postos de trabalho foram mais prejudicados e o desemprego foi maior, como o emprego doméstico em que, segundo o IBGE (PNAD-Covid, 2020), 747 mil postos de trabalho foram extintos em 2020, e, de outro lado, os trabalhadores do setor de cuidados foram os mais expostos ao contágio. E, por fim, o fechamento de creches e escolas e o isolamento social fizeram com que recaísse totalmente sobre as famílias as tarefas de cuidados, incluindo as tarefas domésticas, os cuidados dispensados às pessoas de alguma forma dependentes, acrescido do auxílio às crianças em aprendizado à distância. Como cultural e socialmente as tarefas de cuidado são vistas como trabalho feminino, as mulheres foram mais sacrificadas com o acúmulo de tarefas. Por causa da impossibilidade de utilizar as redes de apoio (creches, escolas, centros de atenção especializados, avós e outros membros da família e vizinhos/as) para a terceirização das tarefas de cuidado, para muitas famílias a opção "natural" foi a mulher acumular mais essas tarefas ou mesmo "optar" por abandonar o emprego.

\footnotetext{
${ }^{4}$ Estas informações estatísticas são das pesquisas domiciliares do IBGE, Pesquisa Nacional por Amostra de Domicílio Anual (2001-2015) e para a segunda década do século XXI são da Pesquisa Nacional por Amostra de Domicílio Continua (2012-2020), na medida do possível explicitadas no texto.
} 
Isso, além de representar um retrocesso em relação às conquistas das mulheres ao longo do tempo, mostra que a desigualdade estava apenas camuflada, em parte visível no número de horas a mais gastas pelas mulheres com o trabalho não remunerado (21,4 horas semanais) em relação aos homens (11 horas semanais). Durante a pandemia, quando as pessoas na família tiveram que assumir novas tarefas e ficaram sobrecarregadas, a resposta continuou a ser que a mulher assumisse seu posto no comando e gerenciamento da casa, fazendo o necessário para a manutenção do nível de bem-estar social de seus membros.

Portanto, pode-se entender que a pandemia tem impactos imediatos relacionados à saúde das pessoas, cujos métodos disponíveis para o combate, tais como o isolamento social e a proteção individual, têm efeitos econômicos perversos: provocaram o fechamento temporário ou permanente de empresas, causando aumento do desemprego e queda da renda, cujos efeitos são não apenas de curto, mas de longo prazo, na medida que alguns dos postos de trabalho poderão não retornar imediatamente após a estabilização e controle da doença. E, além disso, a pandemia terá efeitos sobre as desigualdades, dentre elas a de gênero, caso as políticas públicas efetivadas durante a pandemia e na fase de retomada das atividades econômicas não estejam especificamente preocupadas e direcionadas às pessoas $\mathrm{e}$ grupos (ou seja, as mulheres) que, neste período, se mostraram mais vulneráveis.

Este texto tem a preocupação de mostrar como a formulação de políticas públicas no combate aos efeitos da pandemia deve incluir a participação das mulheres, tendo como fio condutor a economia feminista e a reprodução social do trabalho e seus impactos sobre as vidas femininas. Desta forma, privilegiando o olhar de gênero e destacando a importância do trabalho não remunerado e os reflexos de sua desigual distribuição entre homens e mulheres, este trabalho traça um quadro dos impactos da crise econômica de 2015 em diante no mercado de trabalho, analisandoo sob a ótica da divisão sexual do trabalho, em torno da qual se estrutura o exercício do poder em nossas sociedades e a discriminação de sexo, raça e identitária na sociedade (KERGOAT, 2019, p.288). 


\section{A deterioração do cenário econômico e a irrupção da pandemia}

A crise econômica brasileira, iniciada no final de 2014, e o deterioramento das contas públicas têm sido combatidos com o uso de políticas restritivas. Desta forma, a primeira foi a aprovação da Proposta de Emenda Constitucional número 55 (a PEC do Teto dos Gastos ou PEC 55, de 15/12/2016), que instituiu o Novo Regime Fiscal e determinou o congelamento dos gastos públicos aos mesmos níveis de 2016 pelos 20 anos seguintes. E como afirma Fagnani (2018, p. 59), desde 2016 tem prevalecido o discurso que justifica a política de austeridade e a implantação do Estado Mínimo como única alternativa de política econômica para o país. E seguiu-se com a aprovação das reformas trabalhista e da previdência social, ambas com forte viés liberal, o que significou a redução de proteção social e trabalhista para famílias que já vivem no limite da pobreza e têm baixa resiliência a crises.

E tanto a reforma da Previdência Social (Emenda Constitucional 103, de 13/11/2019), como a Reforma Trabalhista, aprovada em 2017, agravaram este quadro de penúria das camadas mais pobres da sociedade. A Reforma Trabalhista reduziu parte da estrutura de proteção ao trabalho estabelecida na Consolidação das Leis do Trabalho (CLT, de 01 de maio de 1943). A nova lei permite formas de contratação de mão de obra sem configurar vínculo trabalhista, que significa sem a garantia de direitos protetivos ao trabalho, prevalecendo o negociado sobre o legislado ${ }^{5}$, e também permite a contratação de mão de obra para trabalho intermitente e terceirizado. Esta reforma levou também à redução do acesso dos trabalhadores aos recursos na Justiça do Trabalho ao estabelecer que os custos do processo, referentes às ações trabalhistas, seriam de responsabilidade do perdedor da ação. $O$ temor de perder a ação faz com que a parte mais frágil, o/a trabalhador/a, seja excluída do caminho da Justiça para dirimir conflitos.

Desde 2015 o Brasil tem apresentado baixo desempenho econômico, com taxas negativas de crescimento do PIB em 2015 e 2016, de $-3,5 \%$ e $-3,3 \%$, respectivamente, e baixo crescimento nos anos seguintes, crescendo apenas $1,3 \%$ em 2017, 1,8\% em 2018 e 1,1\% em 2019 (IBGE, Contas Nacionais). A leve recuperação nos três últimos anos não promoveu melhorias iguais entre os diversos

\footnotetext{
${ }^{5}$ Esta mudança está escrita: "No artigo 611-A do texto da Reforma, há previsão de que o negociado deve prevalecer sobre o legislado, violando a construção do direito internacional do trabalho no sentido de que as negociações devem melhorar as condições de trabalho" (Artur, 2020, p.28).
} 
segmentos sociais. Esta deterioração da economia implicou em aumento da desigualdade de renda e dos níveis de pobreza, que estavam em queda desde 2003 (DWECK, 2019). Segundo os dados do IBGE (Síntese de Indicadores Sociais, 2019), o rendimento dos $10 \%$ mais ricos da população, em 2018, era 13 vezes maior que o rendimento dos 40\% mais pobres, índice que tem aumentado desde 2015 . Foi neste quadro de crise econômica e alto desemprego que a economia foi impactada pela pandemia da Covid-19.

\section{O mercado de trabalho em tempos de pandemia: gênero e cuidados}

O trabalho está na base da produção do viver em sociedade, sendo um mediador das relações sociais. No século $X X$ a vida das mulheres teve muitas transformações relativas à forma de engajamento delas na sociedade. No Brasil, desde o final dos anos 1980 as mulheres mantêm uma média de anos de estudos superior à média dos homens, mas isso não se refletiu em igualdade de participação ou de remuneração no mercado de trabalho, o que mostra que a diferença de rendimentos entre homens e mulheres vai além da qualificação (MORANDI e MELO, 2019). De forma geral, as mulheres continuam mais presentes que os homens nas atividades de cuidados, remuneradas ou não ${ }^{6}$. Nos últimos setenta anos, como mostram os gráficos 1 e 2 , a participação das mulheres na força de trabalho brasileira continuou proporcionalmente menor que a dos homens, passando de $13,6 \%$ da população econômica ativa (PEA), em 1950, para 44,1\% em 2000 (Censo Demográfico, IBGE), patamar que não se alterou significativamente nos anos seguintes, ficando em torno de $43 \%$ das mulheres e $72 \%$ dos homens em 2018 e 2019 (IBGE, PNAD Contínua).

${ }^{6}$ Atividades relacionadas à reprodução da vida como educação, saúde, serviço social, trabalho doméstico, serviços de alojamentos e alimentação. (Melo e Thomé, 2018). 
Gráfico 1: População economicamente ativa, segundo o sexo, 1950-2010

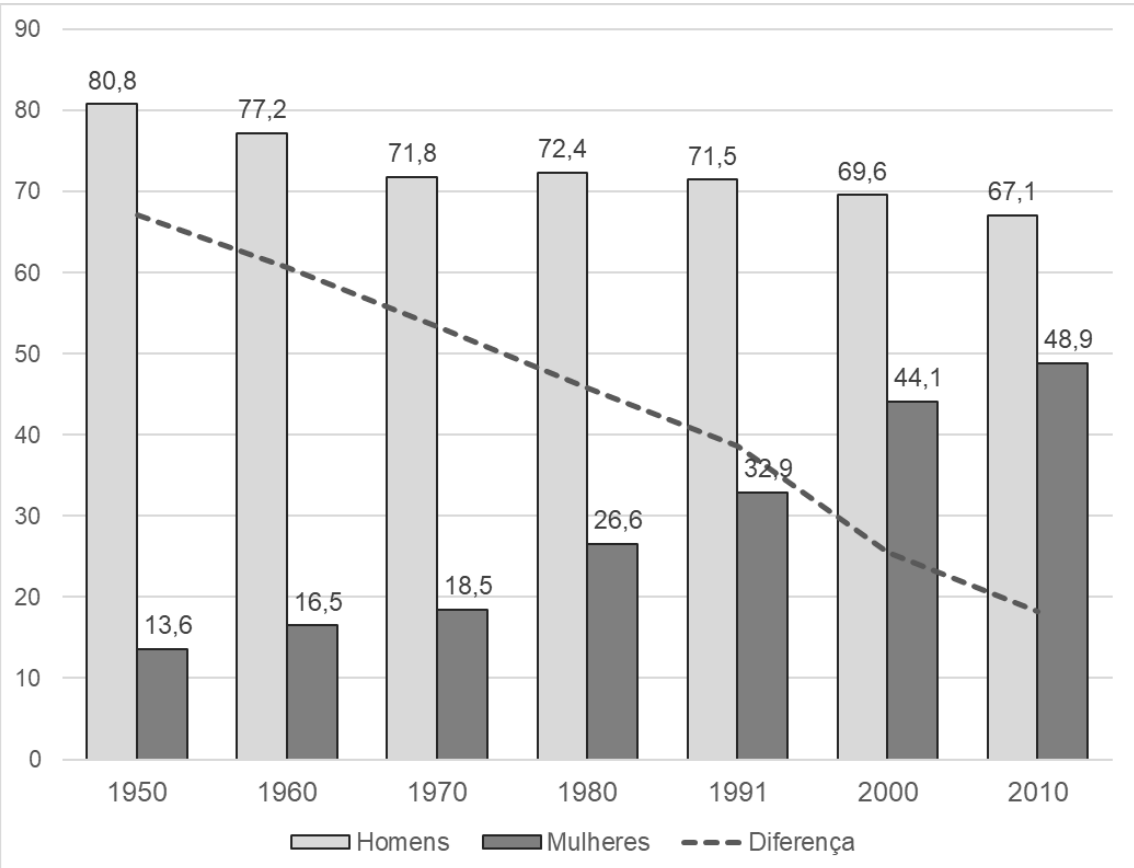

Fonte: IBGE, Censos Demográficos (1950-2010).

Gráfico 2: População economicamente ativa, segundo o sexo, 1995-2015

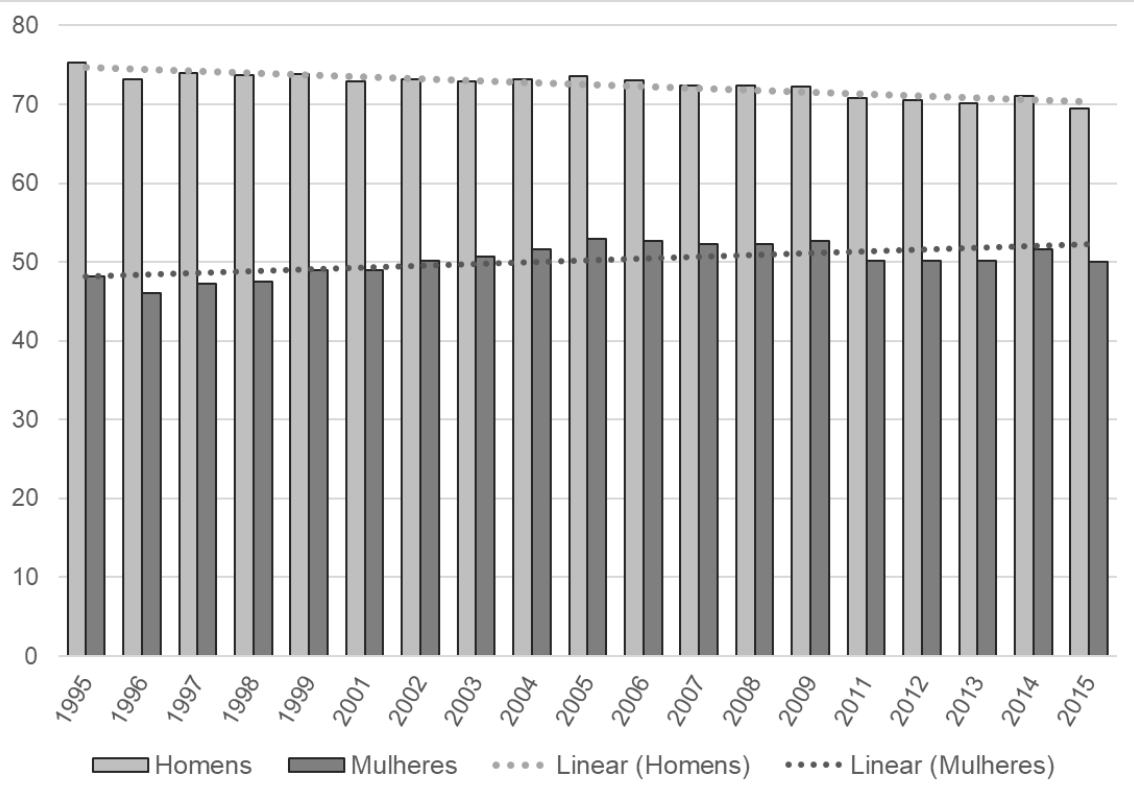

Fonte: IBGE, PNAD-Anual (1995-2015)

No geral, as mulheres estão pouco representadas em setores produtivos identificados tradicionalmente com atividades masculinas, como construção civil, engenharias e ciências exatas e de tecnologia, áreas que tipicamente apresentam melhor remuneração. A maior responsabilidade com os cuidados da família e a maior representação feminina nos setores relacionados aos cuidados é apenas parte da 
explicação da diferença de rendimento médio das mulheres ocupadas. Em 2019, os homens tiveram rendimento médio $28,7 \%$ maior que o das mulheres (IBGE, PNAD Contínua) e essa diferença não desaparece mesmo quando se consideram cargos e qualificação semelhantes. De forma geral, as mulheres frequentemente ocupam menos cargos de chefia e gerência. Ou seja, apesar do aumento do nível educacional das mulheres, persiste uma sociabilidade entre as pessoas que molda o comportamento homens/meninos e mulheres/meninas e se traduz em desigualdade de gênero, também no mercado de trabalho (MELO e THOMÉ, 2018).

A perspectiva teórica da economia feminista ${ }^{7}$ agrega o conceito de divisão sexual do trabalho e denuncia o problema da invisibilidade do trabalho não remunerado, que engloba as tarefas relacionadas aos cuidados, necessárias à reprodução da vida e ao bem-estar, realizadas majoritariamente por mulheres em prol dos demais membros da família. A distribuição desigual do trabalho não remunerado dentro das famílias sobrecarrega o tempo gasto pelas mulheres no trabalho (remunerado e não remunerado), gerando o fenômeno da escassez de tempo vivido pelas mulheres, que têm menos tempo para se dedicar ao trabalho remunerado, às atividades de aprendizagem, menos horas de lazer e de cuidado de si mesmas, menos tempo para qualificação. Isto contribui para que as mulheres fiquem em desvantagem em relação aos homens na competição por espaço e carreira no mercado de trabalho (KERGOAT, 2019).

As estatísticas mostram que não basta as mulheres buscarem maior nível educacional ou concorrer em novos campos de trabalho. As diferenças de rendimento permanecem mesmo quando elas têm nível de escolaridade ou assumem cargos e posições semelhantes às dos homens. Portanto, são necessárias políticas públicas que promovam uma divisão mais igualitária do trabalho não remunerado como uma das mudanças necessárias para eliminar as diferenças de rendimento entre homens e mulheres, aumentar e melhorar a participação delas no mercado de trabalho para reduzir sua dependência econômica, reduzir a feminização da pobreza e promover o

\footnotetext{
7 Segundo Enriquez (2015, p. 30), a economia feminista é uma corrente de pensamento heterodoxo preocupada em visibilizar as dimensões de gênero da dinâmica econômica e suas implicações para a vida das mulheres. Sua noção de "economia do cuidado" contribui para atualizar o debate feminista sobre as formas de organização da reprodução social e reconhece o impacto destas na reprodução da desigualdade. E, como afirma Carrasco (2006), pretende-se com a economia feminista uma mudança radical da análise econômica para que integre e analise a realidade de mulheres e homens, tendo como princípio básico a satisfação das necessidades humanas.
} 
empoderamento das mulheres, contribuindo também para a redução da violência contra as mulheres (CARRASCO, 2011).

Durante a pandemia do Coronavírus, a rede de apoio das mulheres para a terceirização das tarefas domésticas e de cuidado dispensadas à família foi eliminada ou seriamente reduzida pelo necessário distanciamento social e fechamento de escolas e creches, o que agravou a sobrecarga de trabalho das mulheres. As mulheres assumiram mais tarefas e inclusive deixaram o emprego para cuidar da família, o que agravou e deixou mais visível a desigualdade de gênero.

No Brasil, esta sobrecarga é mostrada quando se compara as jornadas de trabalhos de ambos os sexos: a jornada de trabalho total dos homens (trabalho principal mais afazeres domésticos) foi de 53,1 horas-semanais em 2004, tendo reduzido para 50,5 horas-semanais em 2015; enquanto para as mulheres, a jornada total foi de 57,2 horas-semanais em 2004 e de 55,1 horas-semanais em 2015. Comparando-se o total de horas-semanais trabalhadas, as mulheres têm mais horassemanais que os homens. Quando se comparam apenas as horas-semanais despendidas nos serviços domésticos, as mulheres aumentaram em cinco horas a jornada de trabalho não remunerado entre 2004 e 2015, chegando a 20,5 horassemanais, enquanto os homens mantiveram, a mesma média, de 10 horas-semanais ao longo do tempo, como explicitam os gráficos 3 e 4 .

Gráfico 3: Média de horas semanais dedicadas aos afazeres domésticos e cuidados por homens e mulheres com e sem filhos, 2001-2015.

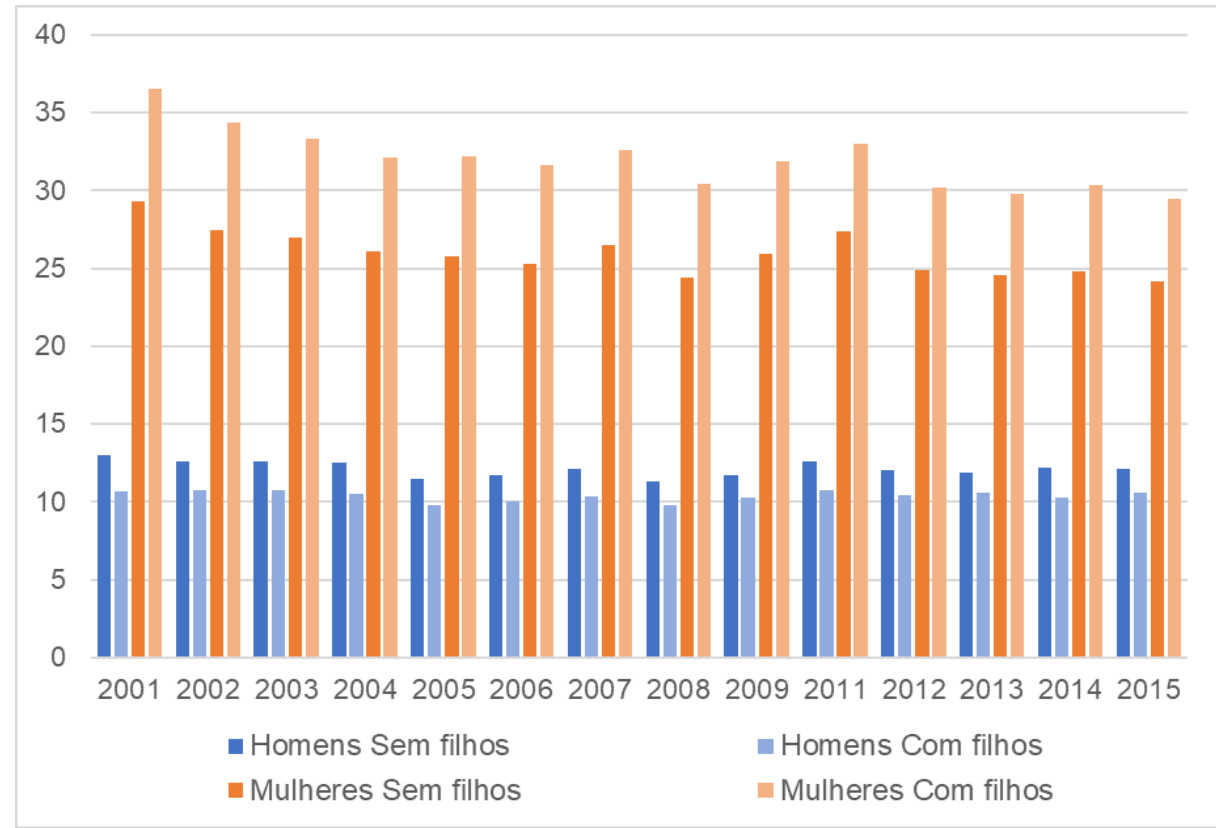

Fonte: PNAD Anual, IBGE (2001-2015), 
Gráfico 4: Média de horas semanais dedicadas aos afazeres domésticos e cuidados por homens e mulheres segundo estado da ocupação, 2001-2015

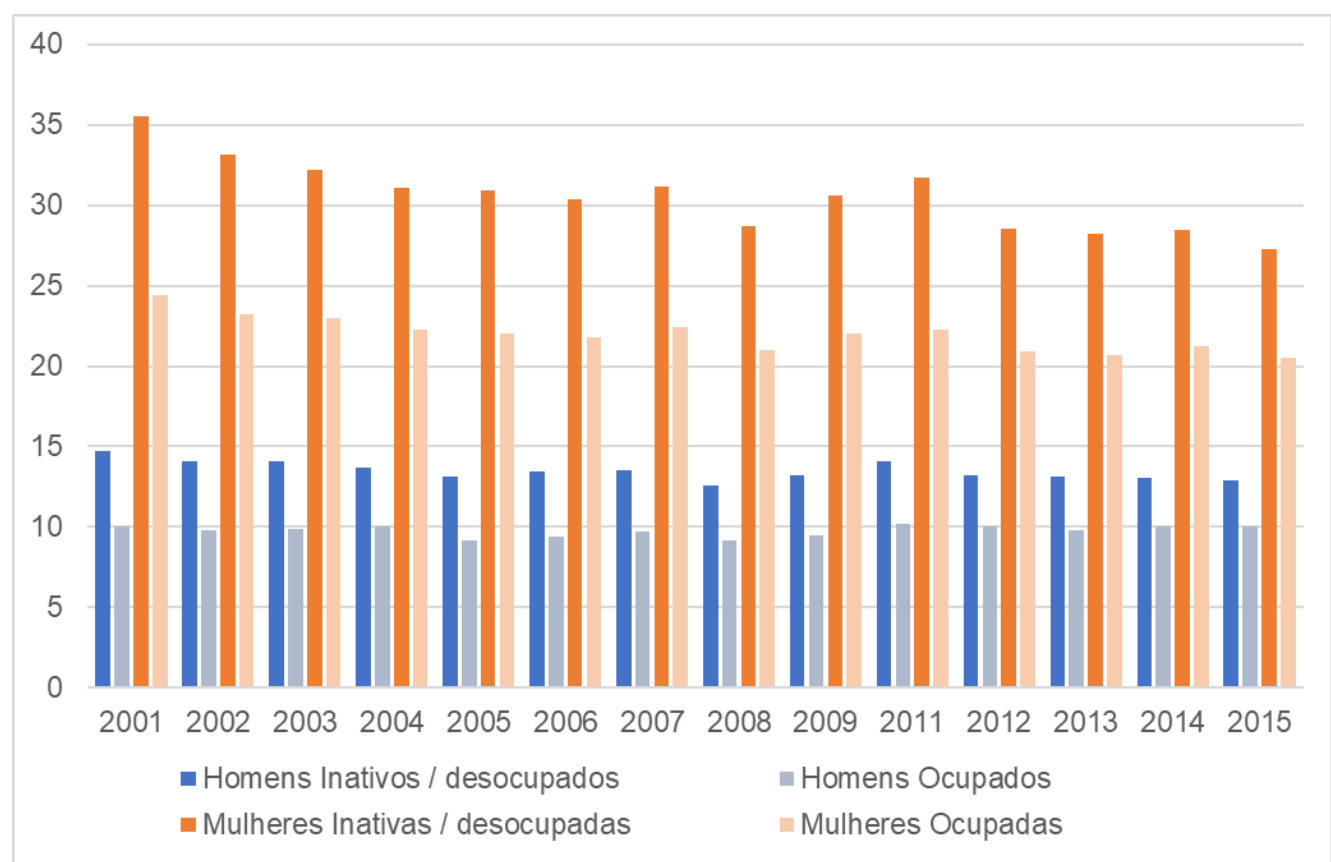

Fonte: PNAD Anual, IBGE (2001-2015),

Assim, como elas têm menos horas de trabalho remunerado, também têm proporcionalmente menor renda. E uma das razões de as mulheres dedicarem menos horas ao trabalho remunerado é a necessidade de cumprirem as tarefas de cuidado da família. Para ajustar a carga horária de trabalho remunerado com a de trabalho não remunerado, uma solução comum é assumir trabalhos de horário flexível ou de meio expediente, o que acarreta desvantagens para as mulheres na competição por maiores salários e melhores cargos no mercado de trabalho (IBGE, PNAD Anual, vários anos).

Desde final de 2014, no início da crise econômica brasileira, o emprego informal tem aumentado na proporção do aumento do desemprego. Nas crises econômicas, o emprego informal termina sendo a solução para a perda do emprego sempre que a economia não dispõe de redes de auxílio social suficientes para dar suporte às famílias que perderam renda. E como, geralmente, este tipo de emprego (o chamado "bico") implica menor rendimento, ele também contribui para o empobrecimento das pessoas das camadas mais baixas de renda. A pandemia fechou inclusive postos de trabalho informais, agravando o quadro de empobrecimento e perda de renda destas famílias. 
Mesmo antes da pandemia, a crise econômica já havia provocado o deslocamento da mão de obra do trabalho formal (com carteira assinada) para o informal (como mostra o gráfico 5). Os dados mostram que, em 2017, $82 \%$ dos novos postos de trabalho foi ocupado por mulheres pretas/pardas, sendo que grande parte delas $(71,2 \%)$ estava trabalhando em serviços domésticos remunerados sem carteira assinada e as demais eram trabalhadoras por conta própria (como ambulantes e cuidadoras). Outra consequência da crise econômica foi o aumento do microempreendedorismo individual, maioria de mulheres, com destaque para os setores industriais (alimentos, vestuário), serviços e atividades de comércio (TEIXEIRA, 2018, pp. 286-293). Muito provavelmente, parte importante dos negócios das mulheres microempreendedoras é informal, sem registro oficial de empresa.

Gráfico 5: Brasil, taxa de desemprego e de informalidade (\%), 2012-2019

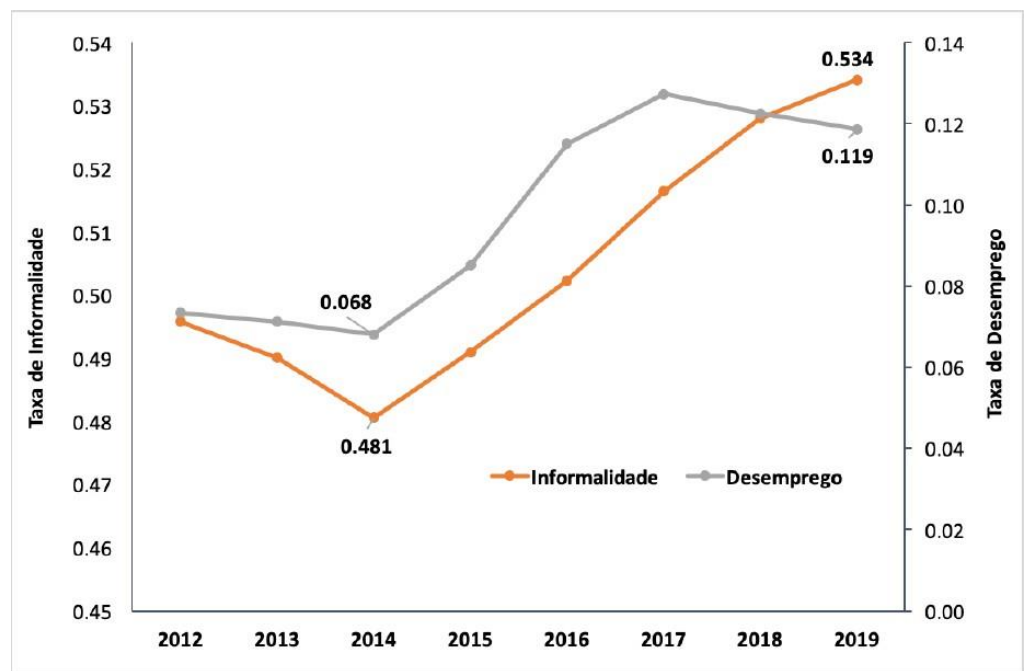

Fonte: Ulissea (2020), PNAD Contínua (IBGE).

A reforma trabalhista, que reduziu tanto proteções sociais ao trabalhador/a, como os entraves legais para contratação e demissão de empregados/as, além de ampliar as possibilidades legais de terceirização do trabalho, também prometia a redução significativa dos custos relativos à mão de obra e, com isso, esperava promover uma expansão significativa de novos postos de trabalho, com impacto positivo sobre emprego e investimentos. No entanto, isto não ocorreu, muito provavelmente porque as reformas não implicaram o fim da crise econômica e a volta de expectativas positivas sobre crescimento econômico. O discurso oficial de que era fundamental viabilizar o ajuste fiscal para estimular o investimento privado, que seria 
a alavanca do novo ciclo econômico, não se concretizou e a economia cresceu pouco mais de 1\% ao ano entre 2017 e 2019 (CARVALHO, 2020; DWECK, 2019).

Com o advento da crise sanitária provocada pela Covid-19 e a ausência de medicamentos ou vacina apropriadas, o distanciamento social foi a solução apresentada pelas equipes científicas que acompanharam o desenvolvimento e avanço do contágio. O impacto do distanciamento social foi mais significativo nos setores e atividades que envolviam contato direto entre pessoas, com destaque para o setor de serviços, com as atividades sendo interrompidas e vários estabelecimentos ficaram fechados. Foi o caso de restaurantes e afins, hotéis, transporte aéreo, salões de beleza, de manicura, empregadas/os domésticas/os e cuidadoras foram dispensadas temporariamente ou de forma definitiva. Como o setor de serviços congrega muitos trabalhadores e pequenos negócios informais, o distanciamento social teve um importante impacto, neste setor, sobre o emprego e a renda ${ }^{8}$. Como estes/as trabalhadores/as informais não têm registro foi mais difícil identificá-las para receberem o auxílio emergencial. A pandemia escancarou a pobreza da sociedade brasileira, e o enorme contingente de pessoas que vivia à margem da sociedade. Esta perda de renda e emprego, principalmente em setores da economia em que as mulheres têm maior participação, é preocupante pelo aumento percentual de domicílios chefiados por mulheres, que passou de 25\% em 1995 para 45\% dos domicílios em 2018 (IBGE, PNAD anual e PNADC).

$\mathrm{Na}$ atual recessão, os homens sofreram com a perda de emprego e redução salarial sem que isso implicasse ganho de rendimento para as mulheres. Na verdade, em 2017 houve uma inflexão na curva de rendimento médio do trabalho principal das mulheres, acentuando a diferença de rendimento entre homens e mulheres (gráfico 6). O fato de as mulheres terem menor rendimento médio que os homens, serem cada vez mais as responsáveis (chefes) pela família e estarem na informalidade tem impacto também na qualidade de vida de seus dependentes, sendo um fator que contribui para a reprodução da pobreza.

\footnotetext{
${ }^{8}$ As maiores quedas na ocupação foram de empregadores (-13,2\%), autônomos (-16\%), trabalhador/a informal (-23\%) e trabalhadoras/es domésticas/os (-32\%). (IBGE, PNAD-Covid).
} 
Gráfico 6: Brasil, rendimento médio do trabalho principal por sexo, 2012.1-2020.1

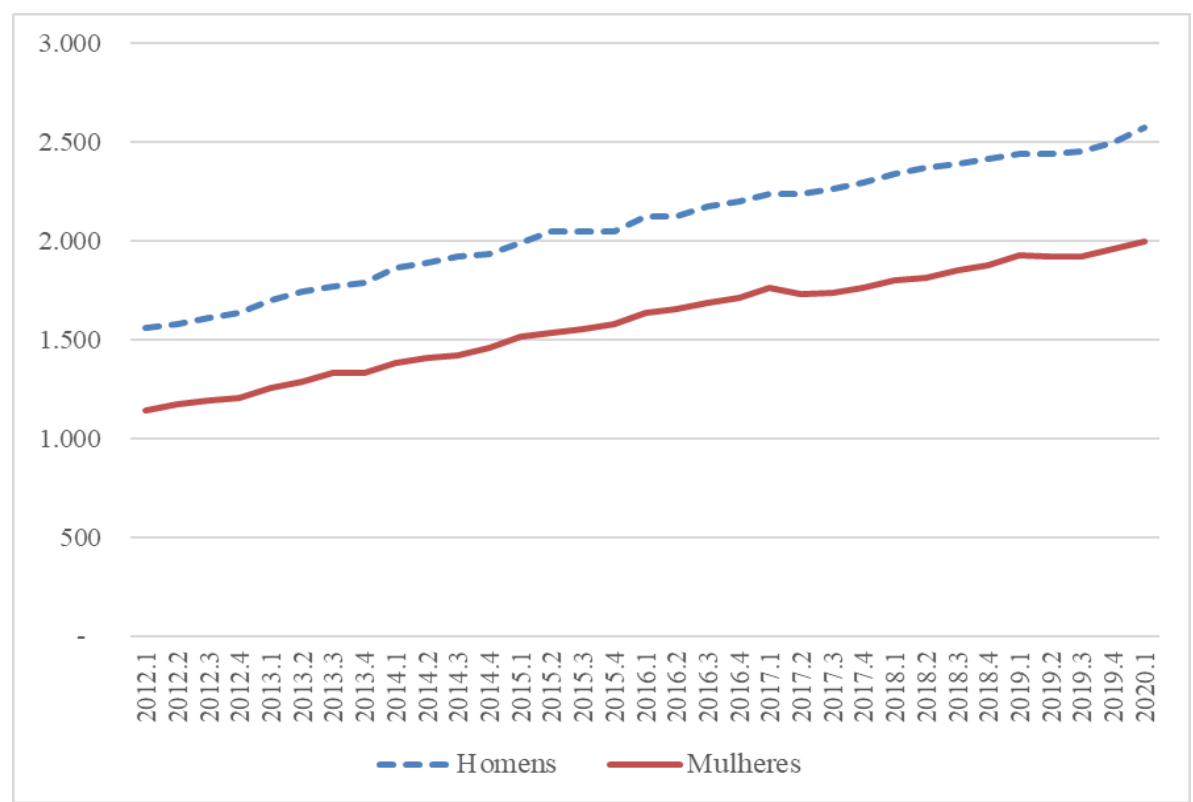

Fonte: PNAD Contínua (IBGE). Elaboração própria.

A quebra desse ciclo vicioso passa por mudanças culturais relativas à divisão sexual do trabalho não remunerado, que também dependem de incentivos econômicos e legais, como a equiparação das licenças maternidade e paternidade. ${ }^{9}$ Nesse sentido, uma contribuição importante de políticas públicas para aumentar a renda média das mulheres é através da oferta de creches e escolas de ensino fundamental de tempo integral, principalmente para as famílias de menor renda. A creche e a escola integral permitem que as mulheres trabalhem em empregos de tempo integral, aumentando a possibilidade de conseguirem emprego formal e terem melhoria de renda, com maior acesso às redes de proteção laboral oficiais.

Algumas questões importantes ficaram mais evidentes durante a pandemia do Covid-19, como a importância do acesso universal à saúde de qualidade, a disponibilidade de rede de água tratada e coleta de esgoto e de lixo, e a boa qualidade e disponibilidade de transporte público. A perda abrupta de renda, sem uma data para o retorno, deixou famílias inteiras sem nenhuma possibilidade de sobrevivência. $O$ auxílio foi fundamental e ainda é essencial, até a volta da economia à nova normalidade. Mas ficou evidente que a renda não resolve todos os problemas. $\mathrm{O}$ descaso com a estrutura de saúde pública das últimas décadas, acrescido do

\footnotetext{
${ }_{9}$ Países nórdicos têm definido uma licença parental que tem incentivado a maior participação efetiva do pai nos primeiros meses da vida do bebê. Ela obriga que ambos os pais utilizem a licença, caso contrário, o tempo de quem não usou é perdido.
} 
negacionismo do governo federal e sua atuação no sentido de desacreditar a ciência, insistir em não coordenar uma ação conjunta para o combate à epidemia, contribuíram para que o número de contaminados e de morte por Covid-19 no Brasil fosse maior do que o que poderia ser. Um dos graves problemas relativo ao enfrentamento da pandemia no Brasil foi a obstinada negativa do governo federal de coordenar as ações necessárias para o controle da expansão do contágio, alternativa viável na ausência de medicamento ou vacina adequados, insistindo numa postura negacionista em relação à ciência. Essa atitude levou, possivelmente, a que o Brasil tivesse mais mortes do que o que poderia ter tido caso o governo federal tivesse assumido o papel de coordenador nacional efetivo. Durante todo o período da pandemia, a preocupação principal do governo federal foi apenas com o aprofundamento da crise econômica imposta pela política sanitária de combate ao vírus e seu impacto sobre as contas públicas. ${ }^{10}$

O Ministério da Economia foi lento em programar medidas de apoio e o fez de má vontade, mais preocupado com o saldo orçamentário do que com a real situação e capacidade de reação da economia caso não houvesse nenhum tipo de repasse monetário às famílias e empresas. Segundo dados da PNAD Covid (IBGE, 2020), $5,2 \%$ dos domicílios (cerca de 3,5 milhões) sobreviveram apenas com o auxílio emergencial que, em média, aumentou em 95\% a renda habitual, com maior impacto nas famílias de menor renda. O auxílio emergencial compensou cerca de $45 \%$ do impacto da pandemia sobre a massa salarial e $67 \%$ da perda de massa salarial das pessoas que continuaram empregadas (IPEA, 2020). ${ }^{11}$

Inicialmente, o projeto de Lei enviado pelos Ministérios da Economia e da Cidadania com a proposta para o auxílio emergencial para pessoas que estavam na informalidade e não recebiam benefícios previdenciários ou assistenciais e tampouco seguro-desemprego, estipulava um auxílio de $\mathrm{R} \$ 200,00$ durante 3 meses. Na Câmara Federal, com a pressão popular e a crítica generalizada ao baixo valor proposto, o valor foi alterado para $R \$ 500,00$ e o governo, para mostrar magnanimidade e sair como o definidor do valor, alterou o valor para $R \$ 600,00$ (Lei 13.982, de 02/04/2020). Foram definidas 3 parcelas pagas através da Caixa Econômica, utilizando o Cadastro

\footnotetext{
${ }^{10} \mathrm{O}$ isolamento social foi a política sanitária adotada pela grande maioria dos países como política vital para reduzir o contágio e reduzir o número de mortes.

${ }_{11} \mathrm{O}$ valor médio do auxílio emergencial foi de $R \$ 846,50$, que correspondeu a $44,6 \%$ do rendimento médio da população ocupada, $77,5 \%$ do rendimento médio dos trabalhadores por conta própria e $21,2 \%$ maior que a média dos rendimentos dos trabalhadores domésticos (IPEA, 2020)
} 
Único disponível no programa Bolsa Família. Durante o processo de discussão na Câmara Federal ficou evidente a fragilidade das mulheres chefes de família, o que levou à alteração e aprovação para que as mulheres chefes de família com filhos menores recebessem $\mathrm{R} \$ 1.200,00$ reais nos três meses. Esta foi uma vitória construída no plenário da Câmara Federal, já que o projeto de lei não tinha considerado esta questão. Esta medida foi muito importante porque as mulheres sozinhas, chefes de família e com filhos menores ${ }^{12}$ são, em grande maioria, trabalhadoras informais e, consequentemente, muito vulneráveis no quadro da pandemia (entrevista Lucilene Morandi, O Globo, 03/04/2020).

A parte institucional e burocrática para o pagamento do auxílio emergencial não funcionou adequadamente e muitas pessoas demoraram muito tempo para conseguir se cadastrar e receber. As dificuldades estavam relacionadas ao fato de parte dos trabalhadores informais não estar incluída no Cadastro Único e com a não adequação do sistema de atendimento on-line da Caixa Econômica Federal, a operadora bancária do benefício. A discussão, no momento, é sobre a prorrogação do auxílio emergencial porque a pandemia não foi debelada e a taxa de mortalidade ainda continua em centenas diárias. A proposta do governo federal é de prorrogação do auxílio emergencial, agora com novo nome, auxílio emergencial residual, com valor reduzido para a metade, $R \$ 300,00$, a ser pago apenas até o fim do ano, e será estendido automaticamente para todos que receberem o auxílio emergencial em setembro, caso se enquadrem nos critérios da MP 1000/2020. A mulher provedora continua a receber em dobro. (Portal G1, 09/09/2020)

O programa de auxílio do governo federal para as empresas permitiu que estas reduzissem o salário na medida da redução da jornada de trabalho ou mesmo suspendessem contratos de trabalho, sendo a complementação da remuneração arcada pelo programa do governo, tendo como base o seguro-desemprego. Nesse pacote de ajudas, as mulheres tiveram destaque nos casos específicos das empregadas domésticas, tendo o mesmo tratamento que os trabalhadores dos demais setores. Com relação às mulheres gestantes, ficou explicitado que também podiam ter seus contratos reduzidos ou suspensos, como os demais trabalhadores, mas continuariam não podendo ser demitidas sem justa causa. As mulheres que estavam,

\footnotetext{
${ }^{12}$ Segundo o IBGE (PNAD Contínua), 87,4\% das famílias com apenas um cônjuge e com filhos são chefiadas por mulheres. O percentual quando se inclui corte de cor e raça não se altera.
} 
durante este período, em licença-maternidade, não poderiam ter alteração nos seus contratos.

A queda súbita da produção e emprego, ocorrida em março, começou a arrefecer em maio, segundo dados da Receita Federal ${ }^{13}$, com leve retorno do nível de vendas após o impacto das medidas de estímulo econômico. O governo federal, ao se recusar a montar uma estratégia de campanha a nível nacional, obrigou a que os governos estaduais e municipais adotassem as medidas necessárias de forma autônoma e isolada, ao mesmo tempo que sofriam pressão - inclusive com ameaças de corte de apoio - do governo central para não adotarem o isolamento social para não paralisar a economia, como se os governos estaduais e municipais tivessem escolha. O resultado foi que o combate à pandemia foi diferente em cada região, dependendo do maior ou menor comprometimento do governo local com o bem-estar da população e dependendo de sua capacidade de mobilizar recursos para as intervenções e ajudas à população que se fizessem necessárias. Certamente o Brasil, por causa de uma falta de liderança nacional para o adequado combate à pandemia, registrou um número elevado de mortes desnecessárias. ${ }^{14}$

Instituições internacionais (CEPAL, 2020; ONU Mulheres, 2020) têm feito diversos apelos e recomendando que os países que enfrentam os impactos do Covid19 deveriam incorporar o enfoque de gênero nas políticas sanitárias e econômicas adotadas. Justifica seu posicionamento alertando que as normas sociais e os padrões culturais são fatores determinantes dos impactos diferenciados desta crise sanitária para mulheres e homens. Os dados da PNAD Covid (IBGE, 2020) mostram que apesar de a taxa de desemprego ter começado a cair em agosto passado, ainda é muito alta (acima de 13\%) e cerca de $29 \%$ das famílias ainda não tem nenhuma renda proveniente de emprego e dependem de programas de repasse de renda. Estes dados reforçam a necessidade da continuidade do auxílio emergencial até que a economia volte efetivamente a crescer.

Um dos temas que esta pandemia também trouxe à tona foi a dimensão da divisão sexual do trabalho em relação ao trabalho não-remunerado, cuidados e afazeres domésticos, realizados para a reprodução da vida no interior das famílias.

\footnotetext{
${ }^{13}$ Boletim da Receita Federal, Impactos da Covid-19, No. 1, 1 de junho de 2020.

14 "Ao minar o trabalho dos profissionais de saúde e se recusar a assumir responsabilidade pela pandemia, os líderes do Brasil e México em particular desencadearam uma onda de mortes desnecessárias" (ENRIQUEZ, CABAL, CENTENO, 2020).
} 
Trabalhadores/as domésticos/as ainda eram, até 201915, um dos maiores contingentes de trabalhadores nacionais, representando 6,3 milhões de trabalhadores/as, ou cerca de $14,6 \%$ dos trabalhadores nacionais, sendo que $92,4 \%$ são mulheres. A renda média de $25 \%$ desses/as trabalhadores/as é de até meio salário-mínimo nacional e apenas 1,6 milhão, ou 25,4\%, tem carteira assinada (IBGE, PNADC, 2018). Os/as trabalhadores/as desse setor precisam de proteção social, porque uma grande maioria está na informalidade e com o isolamento social são mais facilmente dispensados/as, sem terem direito às proteções sociais disponíveis ao trabalhador formal. E, além disso, estão mais expostos/as ao contágio na medida em que são obrigados/as a continuar a trabalhar para terem renda.

A pandemia explicitou a realidade do trabalho doméstico. Pesquisando este tema há alguns anos, estimamos que cerca de 15 milhões de famílias brasileiras empregam algum tipo de trabalhadores/as domésticos/as, seja mensalista ou diarista. $\mathrm{O}$ isolamento social colocou ainda outras questões. Nos estratos de renda média, as tarefas relativas aos cuidados e afazeres domésticos eram divididas entre as mulheres da família e as trabalhadoras domésticas remuneradas. Esta rotina foi alterada pela pandemia e as famílias se viram na dura posição de assumir o risco e manter o/a trabalhador/a doméstico/a ou assumir mais estas responsabilidades, além do trabalho remoto, o auxílio com as aulas on-line das crianças e o cuidado das pessoas idosas ou enfermas da família. Normalmente, os homens, mesmo os mais politizados com relação à divisão destas tarefas, nunca as assumiram como suas. Há grande expectativa com relação ao que este estado caótico, provocado pela pandemia no interior das famílias, poderá trazer de novidade no comportamento das pessoas em relação ao trabalho não remunerado depois da pandemia. Mesmo que os homens não venham a dividir igualitariamente estas tarefas em suas famílias, a pandemia destacou a grande importância desse trabalho, tradicionalmente invisível e desacreditado na sociedade.

A desigualdade social pré-existente amplifica os novos problemas gerados pela crise sanitária e econômica da Covid-19. O fechamento das escolas, com a proibição das atividades presenciais e sua substituição por atividades on-line de ensino, pode

\footnotetext{
${ }^{15}$ Segundo o IBGE (PNAD-Covid, 2020), durante a pandemia foram extintos 727 mil postos de trabalho doméstico. Em abril havia 5,5 milhões de trabalhadores domésticos no país, o menor contingente desde 2012, quando teve início a série histórica da pesquisa. Deste total, apenas 28,5\% (1,5 milhão) possuía carteira de trabalho assinada.
} 
aumentar a desigualdade entre as crianças e jovens para o período pós pandemia. A maior ou menor disponibilidade de meios eletrônicos adequados para o acesso às aulas on-line (computador, tablete ou celular com acesso à internet de qualidade e rápida), além de um espaço individual e adequado para o acesso às aulas, pode ser o grande diferencial entre os estudantes. Sabe-se que a educação é uma forma de quebrar a cadeia da desigualdade, mas estas desigualdades no acesso às atividades on-line poderão acentuar ainda mais as desigualdades e a capacidade de competir dos jovens das diferentes classes de renda no mercado de trabalho, com desvantagem evidente para os de menor renda.

Será que novos tempos se anunciam e podemos ter esperança que a pandemia revele alguma mudança no comportamento dos homens em relação a estas atividades domésticas, incluindo não apenas as atividades que eles já admitem fazer, como cozinhar, ir ao supermercado, jogar bola com a criança, pagar contas na internet? Será que após a pandemia e tudo o que ela nos permitiu perceber em relação à essencialidade do trabalho não remunerado e sua invisibilidade, os homens/companheiros vão substituir o verbo ajudar, quando se referem às tarefas domésticas, para o verbo partilhar? Será que após a pandemia nós todos discutiremos com mais seriedade a importância do trabalho não remunerado e sobre formas de diminuir a desigualdade neste aspecto?

Uma grande preocupação, tanto a nível internacional quanto nacional, é com as pessoas que trabalham nos serviços essenciais de saúde. É preciso incluir também as cuidadoras na categoria de atividades de risco, porque, tanto no Brasil como no mundo, são as mulheres que predominantemente compõem estes serviços. No Brasil, as mulheres preenchem $63 \%$ das vagas de emprego consideradas de grande risco em relação ao Covid-19, ao mesmo tempo que representam apenas cerca de $43 \%$ da força de trabalho do país. A ONU Mulheres também recomenda que o Estado forneça os dados da Covid-19 por sexo, não só para a mortalidade, mas para as pessoas infectadas. É necessário conhecer se há diferenças ou maior vulnerabilidade por sexo na transmissão e taxa de mortalidade relativa ao Coronavírus. ${ }^{16}$

Historicamente, as crises econômicas criam mais desemprego entre as mulheres, com destaque para uma das mais numerosas categorias de trabalhadoras

\footnotetext{
${ }^{16}$ Segundo dados do IBGE (PNADC, 2018), as mulheres são 65\% dos profissionais de saúde, sendo apenas $47,5 \%$ dos médicos $(47,5 \%$ ), sendo maioria ( $80 \%$ ) dos médicos nas faixas de renda mais baixas enquanto os homens são maioria $(51 \%)$ nas faixas de renda mais alta.
} 
brasileiras, as empregadas domésticas, que têm sofrido com desemprego amplificado também em função do relativo empobrecimento das camadas médias da sociedade. A ONU Mulheres tem apelado para que os governos adotem trabalhos flexíveis e proteção para estas mulheres, porque elas acumulam a jornada de trabalho com os cuidados com sua família.

\section{Apressadas reflexões finais em tempos de pandemia}

Nestes tempos de pandemia, quando um atrevido novo vírus derruba as economias mundiais e aplasta todas as sociedades, ressoa o apelo de Phumzile Malambo-Nouka, sub-secretária geral da ONU e diretora executiva da ONU Mulheres quando diz que

\footnotetext{
"há espaço não apenas para resistência, mas para recuperação e crescimento. Onde governos ou empresas implementam proteção à renda, ...evita-se levar as famílias à pobreza. Essa resposta também deve incluir a economia informal, onde a maioria das mulheres ganha a vida trabalhando fora de casa ... Este é um momento de ... reconhecimento da força da solidariedade para os serviços públicos e a sociedade como um todo" (ONU Mulheres, 2020).
}

É preciso que os Estados priorizem as mulheres nos processos de formulação, implementação e avaliação de políticas públicas, em particular políticas de emprego, inclusão social e redução da pobreza. O impacto econômico provocado pela pandemia pode ter efeito relevante sobre duas das principais ocupações femininas, trabalhadora doméstica e cuidadora, e pode significar um impulso a mais para o empobrecimento das famílias de menor renda. Os dados sobre população ocupada, para o primeiro trimestre de 2020, mostram que a população ocupada sofreu um decrescimento de $3,4 \%$ e a das trabalhadoras domésticas um decréscimo de 10,1\% (IBGE, PNADC).

Outro aspecto que deve ser levado em consideração refere-se ao impacto do auxílio emergencial de $R \$ 600,00$ para os trabalhadores informais, resultando em 44 milhões de pessoas beneficiadas. Como ressaltou o professor da Unicamp DariKrein (2020, p.17), no Brasil a força de trabalho tem cerca de 106 milhões de pessoas e mais da metade dos ocupados foram buscar esse auxílio. Mesmo que muitos destes não estejam na inatividade no momento, isso mostra a dimensão da precariedade do povo brasileiro. 
Ainda como reflexões finais, é preciso alertar para o aumento da violência doméstica no Brasil, com aumento, ainda no mês de março/abril, de $9 \%$ de denúncias no Disque 180, em comparação com o mesmo período do ano passado. A violência doméstica não foi um problema apenas brasileiro. Ela explodiu no mundo inteiro com o confinamento das pessoas para deter a pandemia. Segundo o depoimento da juíza titular da vara de violência doméstica do Tribunal de Justiça do Rio de Janeiro, Adriana Mello, a imprensa mostra a preocupação que deve ter o Estado com relação a esta questão tão espinhosa para todas as mulheres. Ela declarou que foram registrados 724 pedidos de medidas protetivas de urgência no plantão judiciário do Estado nos primeiros meses da pandemia e ela teme que as medidas de restrições de circulação possam limitar as denúncias (Jornal O Globo, 03/04/2020, p. 16). A violência doméstica é uma preocupação de todas as sociedades e um dos pontos destacados pela ONU Mulheres nos seus comunicados globais.

No Brasil, o quadro de crise sanitária, humanitária, socioeconômica e de cuidados da Covid-19 elevou a desigualdade de todos, mas esta foi mais intensamente vivida pelas mulheres. A perda de emprego agravou a situação das famílias de menor renda e, porque as mulheres, em média, têm menor rendimento que os homens, pode-se concluir que as famílias monoparentais chefiadas por mulheres foram mais atingidas pela perda de renda. É preciso reconhecer que há uma difícil conciliação entre trabalho e família nos países em que a estrutura de apoio aos cuidados é precária, como no Brasil. Nesse sentido, as mulheres em idade ativa dividem-se entre o trabalho de cuidado na família e o mercado de trabalho, onde tem menor participação que os homens, caracterizando uma situação de maior dependência econômica do sexo feminino. O reconhecimento da necessidade do trabalho de cuidado e sua essencialidade à reprodução da vida e geração de bemestar é importante para que, de um lado, as políticas públicas incluam os recortes de gênero e raça como base de decisão e, de outro lado, precisamos de mudança na postura social em relação ao trabalho dito feminino, o que envolve mudanças culturais com a participação igualitária de homens e mulheres na divisão do trabalho não remunerado, o que demanda esforço educacional e conscientização social. 


\section{Referências}

ARTUR, Karen. "Instituições judiciais trabalhistas brasileiras e a OIT: entre avanços e recuos", In: PESSANHA, Elina Fontes; RODRIGUES, Maria Cristina; BARROSO, Márcia Castro. OIT 100 anos: ações, impasses e perspectivas, Rio de Janeiro: Lumen Juris, 2020, p. 25-36.

CARRASCO, Cristina. La economía feminista: una apuesta por otra Economía. In: GEOGHEGAN, Verónica Serafini (Org.). La economía feminista. Asunción: Secretaria de la Mujer de la Presidencia de la Republica, 2011, p.35-90.

CARVALHO, Laura, Curto-circuito: o virus e a volta do Estado, São Paulo: Todavia, 2020.

CEPAL - Comisión Económica para América Latina y el Caribe. Conferencia de prensa conjunta de CEPAL y OPS. 30 julio 2020. Disponível em: https://www.cepal.org/es/comunicados/cepal-ops-controlar-la-pandemia-requiereconvergencia-articulacion-politicas-salud.

DWECK, Esther. O Brasil em queda livre. Revista Jacobin, $1^{\text {a }}$ ed. especial, 2019, p. 62-70.

ENRIQUEZ, Diana; CABAL, Sebastián Rojas; CENTENO, Miguel A. Latin America's COVID-19 nightmare: lessons from the world's hardest-hit Region. Foreign Affairs, sept. $1^{\text {st }}, 2020$. Disponível em: https://www.foreignaffairs.com/articles/americas/ 202009-01/latin-americas-covid-19-nightmare

FAGNANI, Eduardo. Austeridade e Seguridade: a destruição do marco civilizatório brasileiro. In: ROSSI, Pedro; DWECK, Esther; OLIVEIRA, Ana Luiza M. de (Org.). Economia para poucos: Impactos sociais da austeridade e alternativas para 0 Brasil. São Paulo: Autonomia Literária, 2018, p. 57-82.

IBGE - Instituto Brasileiro de Geografia e Estatística. Síntese dos Indicadores Sociais: uma análise das condições de vida da população brasileira. vários anos.

Coordenação de População e Indicadores Sociais. Rio de Janeiro: IBGE,

. Sinopse do Censo Demográfico 2010. Rio de Janeiro: Ministério do Planejamento, Orçamento e Gestão/IBGE, 2011.

IPEA - Instituto de Pesquisa Econômica Aplicada. Carta de Conjuntura: Mercado de Trabalho, 1ำ, 2ำ e $3^{\circ}$ trimestre, 2020.

KERGOAT, Danièle. O trabalho, um conceito central para os estudos de gênero? In: MARUANI, M. (org.). Trabalho logo existo: perspectivas feministas. Rio de Janeiro: FGV, 2019, p. 287-294. 
KREIN, José Dari. Está na hora de organizar a economia para colocá-la a serviço da vida das pessoas, e não da acumulação privada da riqueza. Revista POLI, ano XII, no 70, mai-jun. Rio de Janeiro: FIOCRUZ, 2020.

MELO, Hildete Pereira de; THOMÉ, Debora. Mulheres e poder: histórias, ideias. Indicadores. Rio de Janeiro: FGV, 2018.

O GLOBO. Coronavírus: pandemia impacta as mulheres de forma diferente. E isso precisa ser levado em conta para enfrentar a crise. Caderno Celina. Rio de Janeiro, 30 abr. 2020. Disponível em: https://oglobo.globo.com/celina/coronavirus-pandemiaimpacta-as-mulheres-de-forma-diferente-isso-precisa-ser-levado-em-conta-paraenfrentar-crise-24330849.

ONU Mulheres. COVID-19: Mulheres à frente e no centro. 27 Marzo 2020. Disponível em: http://www.onumulheres.org.br/noticias/covid-19-mulheres-a-frente-eno-centro/

PORTAL G1. "Auxílio emergencial residual tem novo valor e novas regras para prorrogação até o fim do ano", 09/09/2020. Disponível em: https://g1.globo.com/sp/ribeirao-preto-franca/pode-

perguntar/noticia/2020/09/09/auxilio-emergencial-residual-tem-novo-valor-e-novasregras-para-prorrogacao-ate-o-fim-do-ano-entenda.ghtml.

TEIXEIRA, Marilane O., "A crise econômica e as políticas de austeridade: efeitos sobre as mulheres", In: ROSSI, P., DWECK, E., OLIVEIRA, A. L. M. de. Economia para poucos, impactos sociais da austeridade e alternativas para o Brasil. São Paulo: Autonomia Literária, 2018, pp. 281-300.

ULISSEA, Gabriel. "Efeitos da Covid-19 no mercado de trabalho brasileiro". Webinar IPEA, 17 de junho de 2020. 